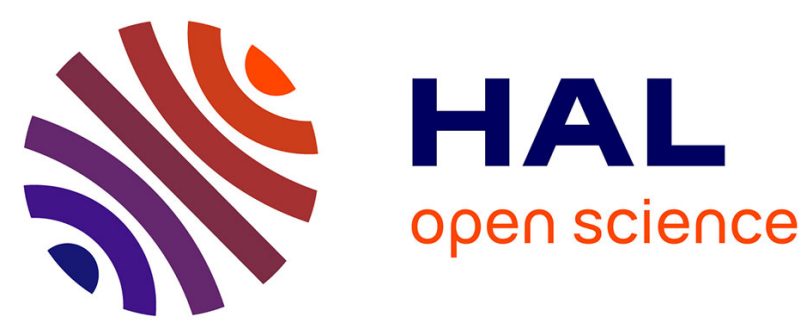

\title{
Experimental validation of green wood peeling assisted by IR heating - some considerations of the analytical system design
}

Anna Dupleix, Jean-Christophe Batsale, Andrzej Kusiak, Mark Hughes, Louis Etienne Denaud

\section{To cite this version:}

Anna Dupleix, Jean-Christophe Batsale, Andrzej Kusiak, Mark Hughes, Louis Etienne Denaud. Experimental validation of green wood peeling assisted by IR heating - some considerations of the analytical system design. Holzforschung, 2014, 68 (8), pp.957-964. 10.1515/hf-2013-0105 . hal-01393711

\section{HAL Id: hal-01393711 \\ https://hal.science/hal-01393711}

Submitted on 8 Nov 2016

HAL is a multi-disciplinary open access archive for the deposit and dissemination of scientific research documents, whether they are published or not. The documents may come from teaching and research institutions in France or abroad, or from public or private research centers.
L'archive ouverte pluridisciplinaire $\mathbf{H A L}$, est destinée au dépôt et à la diffusion de documents scientifiques de niveau recherche, publiés ou non, émanant des établissements d'enseignement et de recherche français ou étrangers, des laboratoires publics ou privés. 
Anna Dupleix*, Jean-Christophe Batsale, Andrzej Kusiak, Mark Hughes and Louis Etienne Denaud

\section{Experimental validation of green wood peeling assisted by IR heating - some considerations of the analytical system design}

\begin{abstract}
The results of a 2D simulation model have been validated by experimental data to check the possibility of infrared (IR) heating of rotating green logs in the course of veneer production. The assumption that the experimental situation can be described by simplified analytical solutions has been confirmed. In the knowledge of the thermal and physical characteristics of green wood, two methods are now available to calculate rapidly the temperature within the wood log and the maximum surface temperature reached by a green log rotating under an IR heating source: (1) by numerical simulation and (2) by analytical equations, which are simpler than the computationally intensive finite element method. Experimental results, validated by both methods, show that an IR heating system as part of an industrial peeling machine would not warm-up green wood to the required peeling temperature at current peeling speeds.
\end{abstract}

Keywords: green wood, numerical model, online infrared heating, temperature field

\footnotetext{
*Corresponding author: Anna Dupleix, Arts et Metiers ParisTech LaBoMaP, Rue Porte de Paris, F-71250 Cluny, France, e-mail: anna.dupleix@ensam.eu; and School of Chemical Technology, Department of Forest Products Technology, Aalto University, FI-00076 Aalto, Finland
}

Jean-Christophe Batsale: Arts et Metiers ParisTech I2M, Esplanade des Arts et Metiers, F-33405 Talence Cedex, France

Andrzej Kusiak: Universite Bordeaux 1, 12M, Esplanade des Arts et Metiers, F-33405 Talence Cedex, France

Mark Hughes: School of Chemical Technology, Department of Forest Products Technology, Aalto University, Fl-00076 Aalto, Finland Louis Etienne Denaud: Arts et Metiers ParisTech LaBoMaP, Rue Porte de Paris, F-71250 Cluny, France

\section{Introduction}

For certain species, the veneer peeling process requires the preheating of round green wood to temperatures ranging from $30^{\circ} \mathrm{C}$ to $90^{\circ} \mathrm{C}$. This is necessary to increase the deformability of wood, to reduce the severity of lathe checking in the veneers, and to reduce the cutting forces. The preheating is usually done by immersing the logs in hot water (soaking). However, this current praxis has a number of disadvantages. These include the duration of the process, water pollution, the need for sophisticated handling, stock downtimes, and a loss of the cohesion and durability of the wood itself (Dupleix et al. 2011). Recent research on beech, birch, and spruce (Dupleix et al. 2012b) has demonstrated that conventional soaking temperatures can be lowered to $50^{\circ} \mathrm{C}$ at the wood cutting plane while still retaining acceptable peeling characteristics in terms of veneer quality (thickness variation, lathe check depth, and distribution). As demonstrated by Grimhall and Hoel (1983), a possible alternative to the traditional log soaking is the infrared (IR) heating of green wood. In this approach, IR heaters are integrated into the peeling machine and heat the round green wood before peeling in a manner similar to that of the laser heating sources used in the metal machining industry to soften the workpiece ahead of the cutting tool (Rahman Rashid et al. 2012; Braham-Bouchnak et al. 2013). In principle, IR heating could lead to the required temperature because $70-90 \%$ of incident IR radiation is absorbed at the surface to a depth of about $0.3 \mathrm{~mm}$ (Dupleix et al. 2012c). Heat then penetrates the green wood by conduction, with diffusivities between 0.12 and $0.32 \mathrm{~mm}^{2} \mathrm{~s}^{-1}$, while the values are decreasing with increasing moisture content (MC) (Dupleix et al. 2012d). The choice of IR technology was also motivated by the potential ease with which IR heaters could be integrated into peeling machines and by the power it offers, which enable a rapid heating, in line with the high peeling speeds (from 1 to $5 \mathrm{~m}$ $\left.\mathrm{s}^{-1}\right)$ today.

Previous studies have demonstrated the ability of IR radiation to raise the temperature of the surface and the layers below either for heating (Makoviny and Zemiar 2004) or for drying (Cserta et al. 2012). With heating source flux densities of $126 \mathrm{~kW} \mathrm{~m}^{-2}$, surface temperatures of $50^{\circ} \mathrm{C}$ can easily be achieved by IR heating in green logs of beech, Douglas fir, and okoumé with peeling speeds of $0.25-0.5 \mathrm{~m}$ 
$\mathrm{S}^{-1}$ (Coste 2005). Similar results have also been obtained in spruce logs with peeling speeds at $0.1 \mathrm{~m} \mathrm{~s}^{-1}$; in this case, the logs should be defreezed and the IR flux densities were low (4-20 kW m²) (Bédard and Laganière 2009). Although a higher input power of the IR source helps achieve rapidly the target temperature, the input power must be limited to avoid overheating and eventual burning of the surface (Makoviny and Zemiar 2004; Marchal et al. 2004).

The aim of the present work was to validate experimentally a 2D numerical model of the heating kinetics in a green wood cylinder rotating under an IR heating source for veneer production. This model, developed by Dupleix et al. (2012a), can predict the heating temperatures within wood and could potentially be used to set up the parameters of an IR heating system embedded in a peeling lathe. The surface and subsurface temperatures should be compared. The temperatures will be measured by thermocouples in green wood samples conveyed under an external IR heating source, on the one hand, and calculated (simulated) numerically, on the other hand.

\section{Symbols and materials and methods}

\section{List of symbols}

$\begin{array}{ll}\text { a } & \text { diffusivity } \\ \alpha_{\text {surf }}^{\text {anal }} & \text { analytical values of slopes } \\ \alpha_{\text {surf }}^{\text {simul }} & \text { numerical values of slopes } \\ \mathrm{c} & \text { specific heat } \\ \mathrm{d} & \text { depth } \\ \mathrm{D} & \text { bolt diameter } \\ \Delta \mathrm{MC} & \text { MC changes in the sample during heating } \\ \mathrm{erfc} & \text { complementary error function } \\ \varepsilon & \text { emissivity of the wood surface } \\ \mathrm{h} & \text { heat transfer coefficient } \\ \mathrm{H} & \text { Heaviside function } \\ \mathrm{HF} & \text { heat flux } \\ \mathrm{IR} & \text { infrared } \\ \lambda & \text { thermal conductivity } \\ \mathrm{m}_{\mathrm{f}} & \text { mass of the sample after heating } \\ \mathrm{m}_{\mathrm{i}} & \text { mass of the sample before heating } \\ \mathrm{m}_{\text {od }} & \text { mass of the oven-dried sample } \\ \mathrm{MC}_{\mathrm{i}} & \text { moisture content } \\ \mathrm{MC}_{\mathrm{f}} & \text { moisture content after heating } \\ \mathrm{MC}_{\mathrm{i}} & \text { moisture content before heating } \\ \mathrm{n} & \text { vector normal to the boundary } \\ \mathrm{q} & \text { IR source heat flux } \\ \mathrm{q}_{\mathrm{est}} & \text { estimated heat flux } \\ \mathrm{q}_{\mathrm{mes}} & \text { measured heat flux } \\ \rho & \text { wood density } \\ \mathrm{RHFD} & \text { real heat flux density } \\ \mathrm{s} & \text { peeling speed } \\ \mathrm{t} & \text { time } \\ & \end{array}$

heating time

bolt temperature

temperature attained at depth $\mathrm{d}$

IR source temperature

initial bolt temperature

surface temperature

arc surface of the log heated externally by IR

\section{Experimental challenges}

In general, it is a problem to assess the effective real heat flux (HF) density (RHFD) received by the sample, which is needed as input data for the numerical simulation. Therefore, the RHFD was indirectly calculated from the surface temperatures, if the experimental situation could be reduced to semi-infinite behavior in the 2D Cartesian coordinates (shortly: semi-infinitive approach or simplified approach), which could be described by simple analytical equations. Thus, the numerical simulation of heating rates was validated by a three-step process: (1) Testing the ability of the analytical equations (based on the simplified approach) to describe the IR heating of a green bolt. Then, (2) the RHFD received by the sample was determined by means of these analytical equations relying on the experimental surface temperature and on the inverse deconvolution method according to Beck et al. (1985). (3) The RHFD was integrated into the numerical simulation to compare the experimental curves to those obtained by numerical calculations.

\section{Samples}

Knot-free samples of wood were sawn (quarter, rift, or flat) from the same freshly cut tree into blocks having the following dimensions: $44 \times 35 \times 20 \mathrm{~mm}^{3}$ (see Figure 1 for a rift-sawn sample). Four wood species were in focus: two hardwoods [European beech, Fagus sylvatica L.; birch, Betula pendula Roth] and two softwoods [Douglas fir, Pseudotsuga menziesii (Mull) Franco; spruce, Picea albies (L.) Karst].

\section{Experiments}

The green wood samples were conveyed at a speed (s) of $0.0032 \mathrm{~m} \mathrm{~s}^{-1}$ under an electric IR lamp composed of a quartz tube delivering a

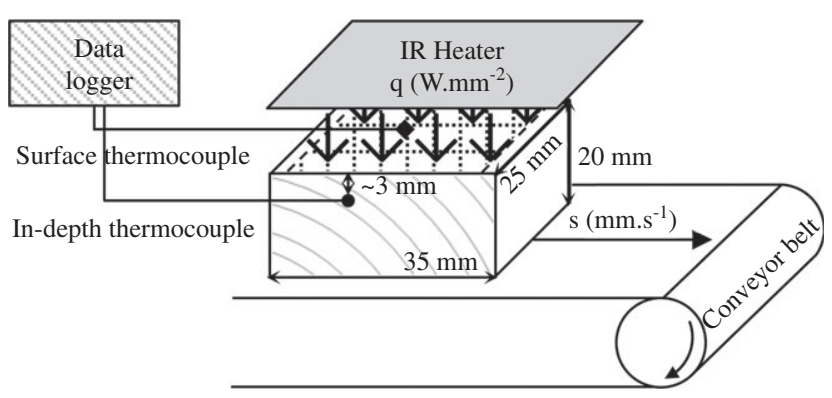

Figure 1 Experimental setup for measuring the surface temperature of a rift-sawn sample under IR heating. 
HFD (q) onto a surface approximately $0.03 \mathrm{~m}$ wide (the gridded surface shown in Figure 1). The samples were shaped in the form of rectangular prisms because (1) it is easier to record the internal temperature rises in a block in motion than in a rotating cylinder and (2) the numerical simulation has demonstrated that the blocks behave in a similar manner to cylinders under the IR conditions applied in the present work. The time-dependent surface temperature was recorded by a surface thermocouple, tightly stapled to the surface to minimize thermal contact resistance. Holes were drilled into the samples at a distance of $3 \mathrm{~mm}$ beneath the exposed tangential surface (Figure 1) to insert the thermocouples for temperature measurements within the block. A tight fit and filling the drilled holes with wood dust after inserting the thermocouples ensured minimal heat losses and thermal contact resistance. The thermocouples were connected to a data acquisition system that recorded the temperature every second. The samples were initially in the green state and at least three replicate tests were performed with different samples (termed "replicates" in Figures 5-7) of each species (both sapwood and heartwood). The MCs before heating $\left(\mathrm{MC}_{\mathrm{i}}\right)$ and after heating $\left(\mathrm{MC}_{\mathrm{f}}\right)$ were determined gravimetrically by means of the following calculations:

$$
\begin{aligned}
& \mathrm{MC}_{\mathrm{i}}(\%)=\frac{\mathrm{m}_{\mathrm{i}}(\mathrm{g})-\mathrm{m}_{\mathrm{od}}(\mathrm{g})}{\mathrm{m}_{\mathrm{od}}(\mathrm{g})} \\
& \mathrm{MC}_{\mathrm{f}}(\%)=\frac{\mathrm{m}_{\mathrm{f}}(\mathrm{g})-\mathrm{m}_{\mathrm{od}}(\mathrm{g})}{\mathrm{m}_{\mathrm{od}}(\mathrm{g})}
\end{aligned}
$$

The changes in $\mathrm{MC}$ during heating $(\triangle \mathrm{MC})$ were calculated:

$$
\Delta M C(\%)=\left(1-\frac{M C_{f}}{M C_{i}}\right) \times 100
$$

\section{Numerical simulation}

The development of log surface and subsurface temperatures over time was simulated by Comsol Multiphysics (Comsol, Inc., Burlington, MA, USA) and MatLab (MathWorks, Inc., Natick, MA, USA) (Dupleix et al. 2012a). The model meshes the log cross-section with 2D finite elements, as the HF in the longitudinal direction can be neglected. An external input HFD (q) was applied to a selected number of surface elements to simulate the rotation of the log in front of the IR source. The temperature distribution was calculated by solving the transient equation for conduction derived from Fourier's law [Eq. (4)]:

$$
\rho c \frac{\partial \mathrm{T}}{\partial \mathrm{t}}=\nabla(\lambda \nabla \mathrm{T})
$$

where $\mathrm{T}$ is the bolt temperature (in $\mathrm{K}$ ), $\rho$ is the density of wood (in $\mathrm{kg} \mathrm{m}^{-3}$ ), $\mathrm{c}$ is the specific heat capacity of wood (in $\mathrm{J} \mathrm{kg}^{-1} \mathrm{~K}^{-1}$ ), and $\lambda$ is the thermal conductivity of the wood (in $\mathrm{W} \mathrm{m}^{-1} \mathrm{~K}^{-1}$ ). The three latter parameters, varying with wood $\mathrm{MC}$, were determined according to the empirical equations developed by Dupleix et al. (2012d). The influence of temperature on $\mathrm{c}$ and $\lambda$ was neglected, because a $40^{\circ} \mathrm{C}$ temperature increase (observed experimentally) leads to a variation in thermal characteristics between $7 \%$ and $12 \%$ according to Suleiman et al. (1999). The initial condition is given by the initial temperature of the bolt, $\mathrm{T}_{\text {init }}=293 \mathrm{~K}$. The boundary conditions at the bolt surface are defined by Eqs. (5a) and (5b) with the vector normal to the boundary (n):

$$
\text { on the arc surface } x:-n \cdot(-\lambda \nabla T)=\varepsilon \cdot q \cdot H(x)
$$

on the rest of the surface: $-\mathrm{n} \cdot(-\lambda \nabla T)=h\left(T-T_{\text {ext }}\right)$

where $\mathrm{H}$ is the Heaviside function (Figure 2); $\varepsilon$ is the emissivity of the wood surface, taken to be 0.85 (Dupleix et al. 2012a); $T_{\text {ext }}$ is the external temperature (in $\mathrm{K}$ ); $\mathrm{h}$ is the heat transfer coefficient (in $\mathrm{W} \mathrm{m}^{-2} \mathrm{~K}^{-1}$ ), and $\mathrm{q}$ is flux density (in $\mathrm{W} \mathrm{m}^{-2}$ ).

\section{Analytical equations}

Assumptions: (1) It is possible to utilize the simplified approach presented in Figure 2, given the large dimension of the bolt diameter (D) compared to $\mathrm{x}$, if the arc surface of the green log is subjected to external IR heating $(x=D / 20)$. (2) In view of the very low thermal diffusivity of green wood (Dupleix et al. 2012d), the behavior can be assumed to be that of a semi-infinite body with a spatially uniform step HF diffusing normal to the surface (x) applied during a heating time $\left(t_{h}\right)$, where $t_{h}=x / s$ and $s$ is the peeling speed (i.e., the constant linear speed at which veneer is generated at the output of the peeling lathe). The problem therefore becomes analogous to a $1 \mathrm{D}$ transient problem, where the spatial variable (x) is replaced by the temporal variable $t_{h}$. With these assumptions, the evolution of the sample surface temperature $\left(\mathrm{T}_{\text {surf }}\right)$ with the square root of time is linear according to Eq. (6) (Taler and Duda 2006):

$$
\mathrm{T}_{\text {surf }}=\frac{2 \mathrm{q}}{\sqrt{\pi} \sqrt{\lambda \rho c}} \sqrt{\frac{\mathrm{x}}{\mathrm{s}}} \text { or } \mathrm{T}_{\text {surf }}=\frac{2 \mathrm{q}}{\sqrt{\pi} \sqrt{\lambda \rho c}} \sqrt{\mathrm{t}}
$$

The exact solution of the temperature $\left(\mathrm{T}_{\mathrm{d}}\right)$ attained at depth (d) within the sample is then given by Eq. (7) [with the diffusivity of wood, $a=\lambda /(\rho c)]$ (Taler and Duda 2006):

$$
\mathrm{T}_{\mathrm{d}}=\frac{2 \mathrm{q}}{\sqrt{\pi} \sqrt{\lambda \rho c}} \mathrm{e}^{-\mathrm{d}^{2} / 4 a t} \sqrt{\mathrm{t}}-\frac{\mathrm{d}}{\lambda} \mathrm{q} \operatorname{erfc} \frac{\mathrm{d}}{2 \sqrt{\mathrm{at}}}
$$

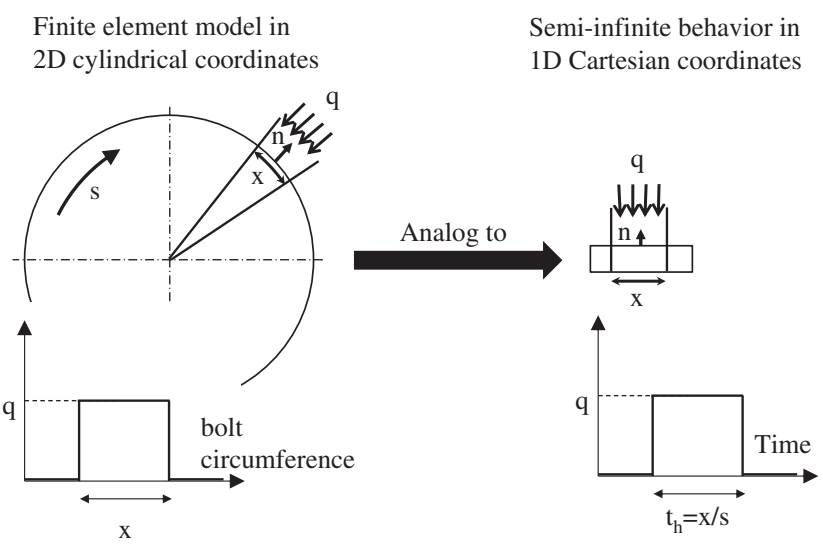

Figure 2 Analogy of finite element model in 2D to semi-infinite behavior in 1D Cartesian coordinates. 
where erfc is the complementary error function that tends to 1 , when time tends to infinity. Therefore, the long-term behavior of $\mathrm{T}_{\mathrm{d}}$ is given by the asymptotic solution obtained when time tends to infinity [Eq. (8)]. It can be seen that, at extended heating times, the temperature at depth (d) also evolves at a rate proportional to the square root of time:

$$
\mathrm{T}_{\mathrm{d}}=\frac{2 \mathrm{q}}{\sqrt{\pi} \sqrt{\lambda \rho c}} \sqrt{\mathrm{t}}-\frac{\mathrm{d}}{\lambda} \mathrm{q}
$$

\section{Results and discussion}

\section{Validating the hypothesis (step 1)}

The validity of the simplified approach shown in Figure 2 would be validated, if the surface temperatures plotted as a function of the square root of time $T_{\text {surf }}=f(\sqrt{t})$ showed the same linear behavior as predicted by the simplified analytical Eq. (6). The natural heterogeneity of wood causes a certain variability of the experimental measurements of $\mathrm{T}_{\text {surf }}=\mathrm{f}(\mathrm{t})$ on the different replicate samples. Therefore, it is more reliable to validate the results of $\mathrm{T}_{\text {surf }}=\mathrm{f}(\sqrt{\mathrm{t}})$ obtained by numerical simulation. Figure 3 shows the results for beech in the early stages of heating (up to $3 \sqrt{s}$ ). The table inserted in Figure 3 summarizes the corresponding results obtained for birch, Douglas fir, and spruce. To keep in close touch with the reality of the experimental cases, the values of the simulation

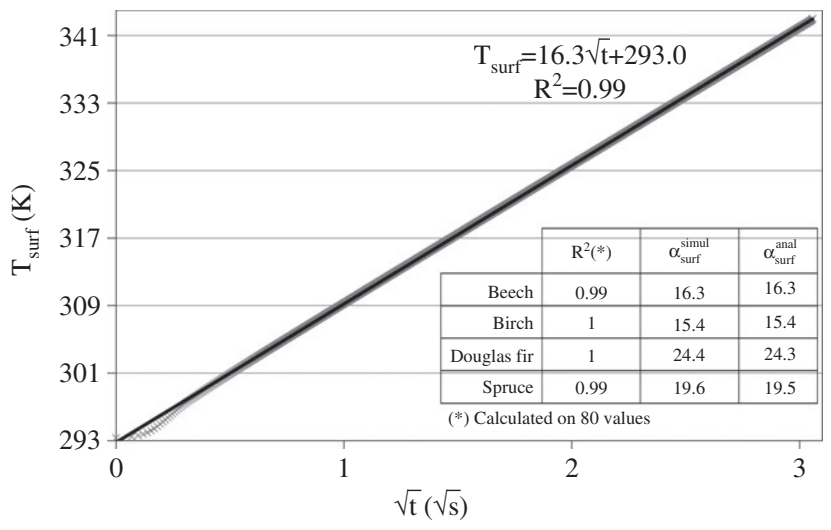

Figure 3 Comparison of finite element simulated surface temperatures of rotating log and analytically calculated surface temperature response of half space.

The temperatures are represented as a function of the square root of time for beech.

Table: Comparison of numerical and analytical values of the slopes $\alpha_{\text {surf }}^{\text {simul }}$ and $\alpha_{\text {surf }}^{\text {anal }}$ of $T_{\text {surf }}=f(\sqrt{t})$ with their corresponding coefficients of determination $\left(R^{2}\right)$ in the case of beech, birch, Douglas fir, and spruce. parameters (rotation speed s, flux density q, and sample MC) and green log thermal parameters (thermal conductivity $\lambda$ and specific heat capacity $\rho c$ ) were the same as those employed in the physical experiments (Table 1).

From the results presented in Figure 3, two conclusions can be drawn. First, the linearity of the relationship $T_{\text {surf }}=f(\sqrt{t})$, confirmed by the high coefficients of determination, validates the assumption that the log can be treated as a semi-infinite body with a step increase in surface temperature of a half-space. Second, for the four species, the near equivalence of $\alpha_{\text {surf }}^{\text {simul }}$ (calculated by linear regression analysis of numerical simulation curves) and $\alpha_{\text {surf }}^{\text {anal }}=\frac{2 q}{\sqrt{\pi} \sqrt{\lambda \rho c}}$ [calculated by inserting the simulation parameters in Eq. (6)] confirms the suitability of Eq. (6) for evaluating the surface temperature increment of a green rotating log under external IR heating based on the simplified approach. The slight difference between $\alpha_{\text {surf }}^{\text {simul }}$ and $\alpha_{\text {surf }}^{\text {anal }}$ in the case of spruce and Douglas fir can be explained by the lack of linearity at the beginning of the curve (which is also visible in the other species) due to a perturbation at the early stages attributable to the numerical simulation.

\section{Determining the effective RHFD (q) received by the sample (step 2)}

From the results above, it is easy to estimate the effective RHFD (q) received by the sample by the inverse deconvolution method according to Beck et al. (1985). Here, the recorded surface temperature data $\left(\mathrm{T}_{\text {surf }}\right)$ are the input to recover the signal q as it existed before it has been convolved by the impulse response of the half-space. The result of the deconvolution gives the maximum value (found to be $\sim 10,000 \mathrm{~W} \mathrm{~m}^{-2}$ ) of the estimated RHFD $\left(\mathrm{q}_{\mathrm{est}}\right)$.

The deconvolution approach may be validated by measuring the spatial profile of the incident radiative $\mathrm{HF}$ received by the sample surface $\left(\mathrm{q}_{\mathrm{mes}}\right)$, which corresponds directly to the electric signal produced by an IR-sensitive sensor placed on the sample surface. For one sample, Figure 4 compares the normalized values of the estimated HFD $\left(\mathrm{q}_{\text {est }}\right)$ with the measured IR sensor signal [which is proportional to the received $\operatorname{HFD}\left(\mathrm{q}_{\text {mes }}\right)$ ] and shows a good agreement between estimation and measurement. This is also a confirmation of the results presented in the first paragraph, which were calculated by Eqs. (6) to (8), that is, the temperature increase in a green log rotating under external IR heating can be described reliably. Figure 4 shows the spatial profile of the effective RHFD received by the sample, which is the input data into the model for the verification of the simulation results. 
Table 1 Thermophysical parameters and their corresponding values used in numerical and analytical simulations.

\begin{tabular}{|c|c|c|c|}
\hline & MC (\%) & $\begin{array}{l}\text { Thermal conductivity } \lambda \\
\qquad\left(\mathrm{W} \mathrm{m}^{-1} \mathrm{~K}^{-1}\right)\end{array}$ & $\begin{array}{r}\text { Heat capacity } \rho c \\
\left(\mathrm{~J} \mathrm{~m}^{-3} \mathrm{~K}^{-1}\right)\end{array}$ \\
\hline Beech & 43 & $0.30(0.003 \mathrm{MC}+0.172)^{\mathrm{a}}$ & $1.6 \mathrm{E}+06(0.019 \mathrm{MC}+0.746)+06^{\mathrm{a}}$ \\
\hline Birch & 85 & $0.45(0.003 \mathrm{MC}+0.191)^{\mathrm{a}}$ & $1.2 \mathrm{E}+06(0.021 \mathrm{MC}+0.577)+06^{\mathrm{a}}$ \\
\hline Douglas fir & 115 & $0.23^{\mathrm{a}}$ & $9.4 \mathrm{E}+05^{\mathrm{a}}$ \\
\hline Spruce & 55 & $0.24(0.002 M C+0.130)^{a}$ & $1.4 \mathrm{E}+06(0.032 M C-0.311)+06^{\mathrm{a}}$ \\
\hline
\end{tabular}

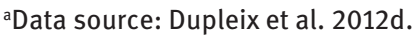

Fixed parameters: rotating speed $0.0032\left(\mathrm{~m} \mathrm{~s}^{-1}\right)$ and density of flux 10,000 $\left(\mathrm{W} \mathrm{m}^{-2}\right)$.

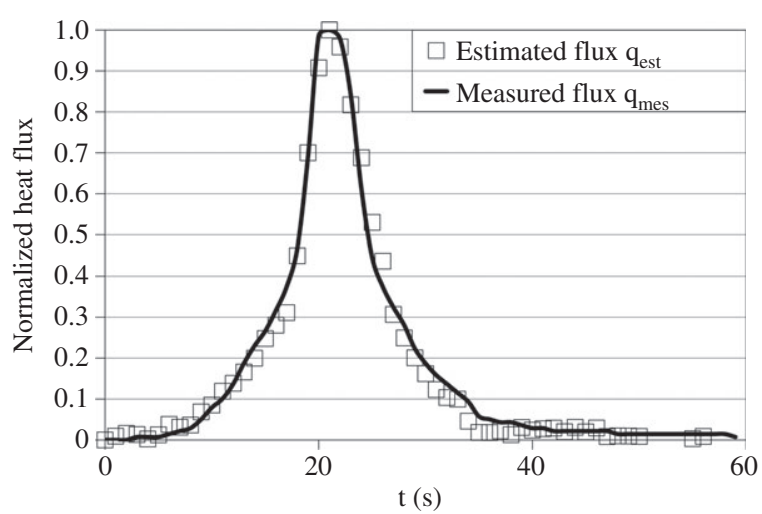

Figure 4 Comparison of the estimated HFD and the measured IR sensor signal on one sample surface (normalized values are represented).

\section{Comparison of experimental and numerical simulation results (step 3 )}

In Figures 5 and 6, the residuals are calculated with the difference between experimental and modeled results and are plotted below each graph. Figure 5a compares the surface temperatures $\mathrm{T}_{\text {surf }}=\mathrm{f}(\mathrm{t})$ of beech at $43 \% \mathrm{MC}$, obtained experimentally from surface thermocouples, with the numerical simulation results modeled with similar parameters (Table 1). Similar results were also obtained for birch at $85 \%$ MC (Figure 5b), Douglas fir at $115 \%$ MC (Figure 5c), and spruce at 55\% MC (Figure 5d). In the 20 first seconds, the increasing slopes of the experimental curves are steeper than simulated (the residuals drop consequently below 0 ). This difference might be explained by some moisture gradients within the wood created during drying. These are responsible for the unavoidable heterogeneities in the thermal properties of wood. Moreover, the variations in the surface emissivities of different wood samples can lead to some errors in the HF received by the samples. However, apart from this difference, these results show a good agreement between the numerical estimation and measurement (as can be seen by residuals that balance $\sim 0$ ). The comparison of temperatures $\mathrm{T}_{3 \mathrm{~mm}}=\mathrm{f}(\mathrm{t})$ obtained experimentally and by numerical simulation is given for several replicates of birch at $85 \%$ MC (Figure 6a), beech at $43 \%$ MC (Figure 7a), Douglas fir at 115\% MC (Figure 6b), and spruce at 55\% MC (Figure 7b). Regardless of the good results, around $\mathrm{T}_{\max }$, the residuals increase. This problem may arise from three side effects: (1) The imprecise insertion depth of the thermocouples; the margin of error in the insertion depth of the thermocouples was estimated to be $\pm 0.5 \mathrm{~mm}$, which clearly might have had an effect. (2) The effect of drying during heating; the difference in the block MC before and after heating ( $\triangle \mathrm{MCs})$ remained low (never exceeding 5\%), although it could not be reliably measured. This change was attributed to water evaporating from the surface layers of the samples. (3) The influence of sawing; the differences in densities (and thus in thermal properties) between earlywood and latewood may have a greater influence in quarter-sawn samples where annual rings are parallel to the IR flux. To take the effect of drying on the thermal properties of wood into account, it is possible to estimate to $50 \%$ the margin of error on the MC. Assuming both effects (1) and (2), the envelope curves for the numerical simulation of $\mathrm{T}_{3 \mathrm{~mm}}$ $=\mathrm{f}(\mathrm{t})$ are plotted in Figure 7 (in dotted lines): in the most favorable case, where both insertion depth and MC are underestimated (Figure 7a plots $\mathrm{T}_{2.5 \mathrm{~mm}}=\mathrm{f}(\mathrm{t})$ at $21 \% \mathrm{MC}$ and $\mathrm{T}_{3.5 \mathrm{~mm}}=\mathrm{f}(\mathrm{t})$ at $65 \% \mathrm{MC}$ for beech), and in the least favorable case, when insertion depth and MC are overestimated (Figure $7 \mathrm{~b}$ plots $\mathrm{T}_{2.5 \mathrm{~mm}}=\mathrm{f}(\mathrm{t})$ at $27 \% \mathrm{MC}$ and $\mathrm{T}_{3.5 \mathrm{~mm}}=\mathrm{f}(\mathrm{t})$ at $83 \%$ MC for spruce). When plotting these envelope curves, the effect of drying (2) dominates over the effect of the imprecise insertion of the thermocouples (1). The envelope curves surround all the experimental curves, which demonstrate that taking into account these two effects is more representative for the real experimental conditions. 

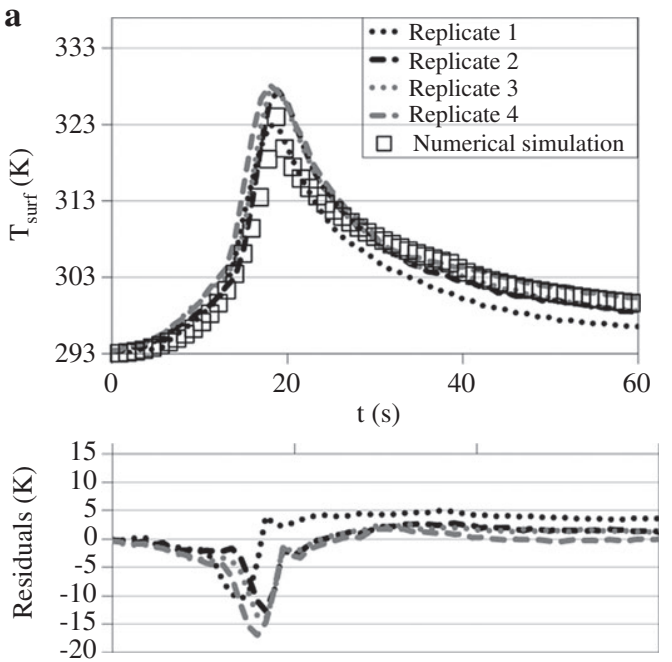

c
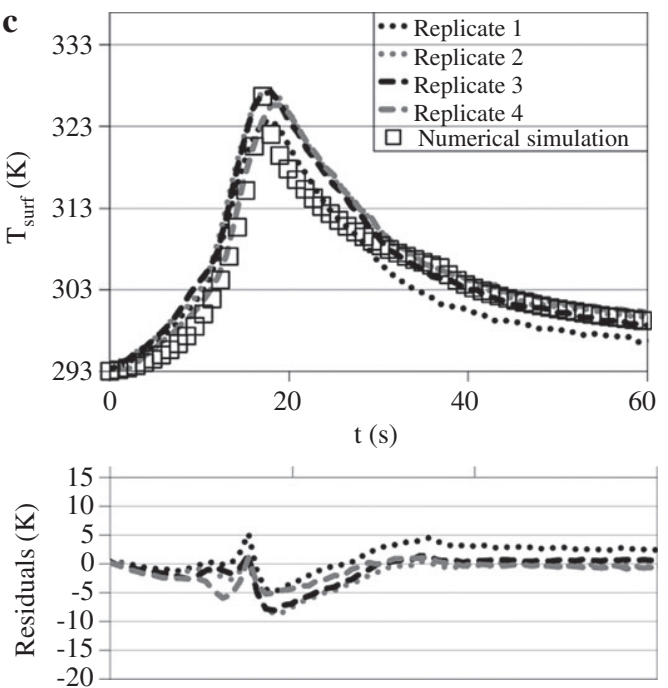

b
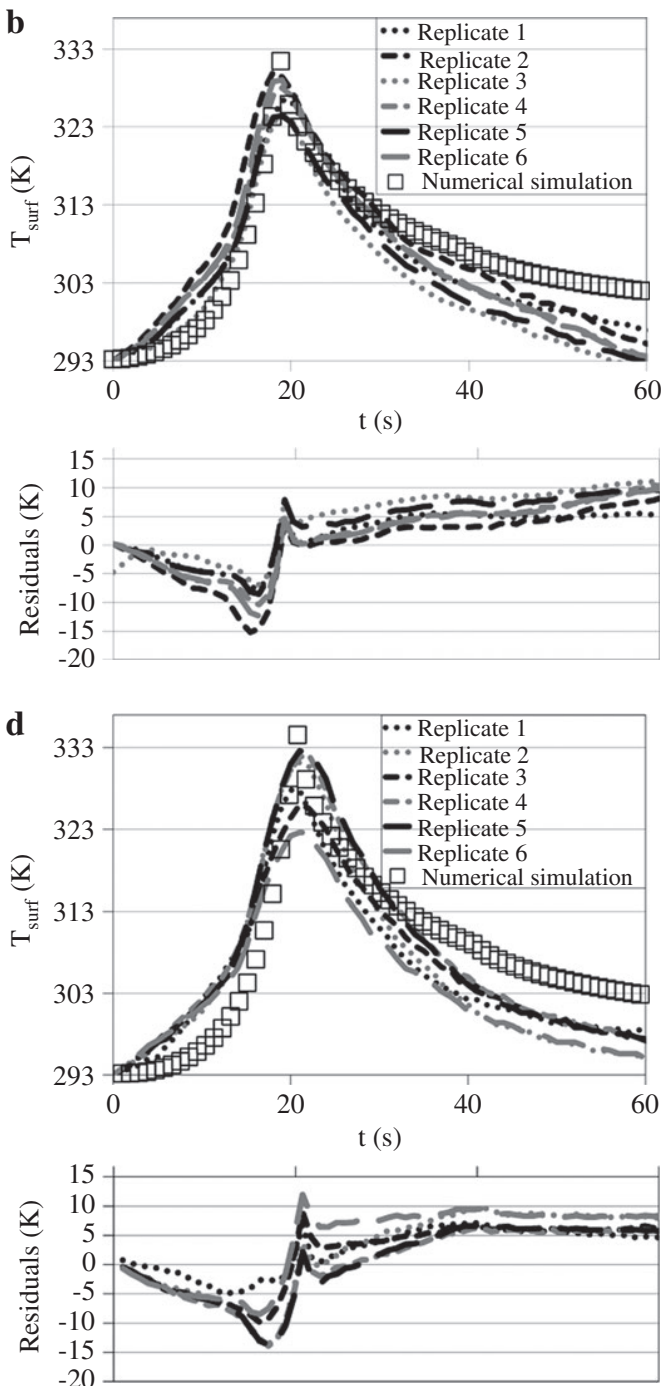

Figure 5 Comparison of numerical simulation curves of surface temperatures $\mathrm{T}_{\text {surf }} \mathrm{f}(\mathrm{t})$ to experimental results obtained on different replicates of (a) beech at 43\% MC, (b) birch at $85 \%$ MC, (c) Douglas fir at 115\% MC, and (d) spruce at 55\% MC (residuals are plotted below each graph).
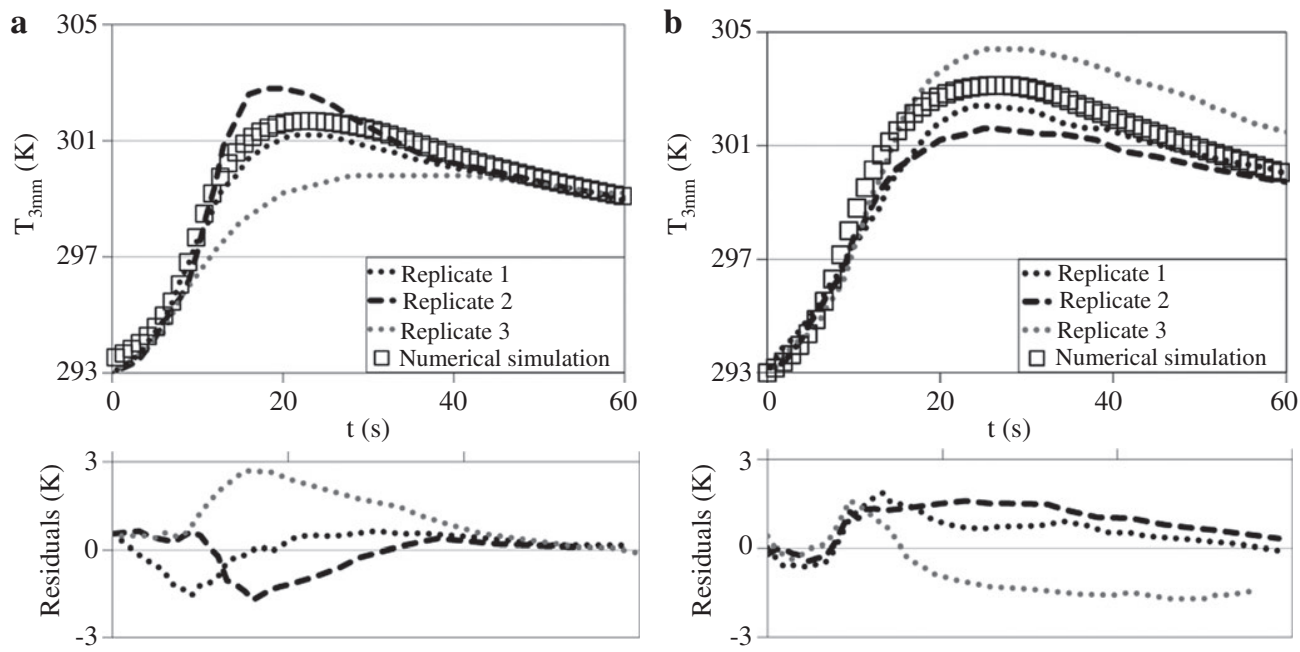

Figure 6 Comparison of numerical simulation curves of temperatures measured at $3 \mathrm{~mm}$ depth $\mathrm{T}_{3 \mathrm{~mm}}=\mathrm{f}(\mathrm{t})$ to experimental results obtained on different replicates of (a) birch at $85 \%$ MC and (b) Douglas fir at $115 \%$ MC (residuals are plotted below each graph). 

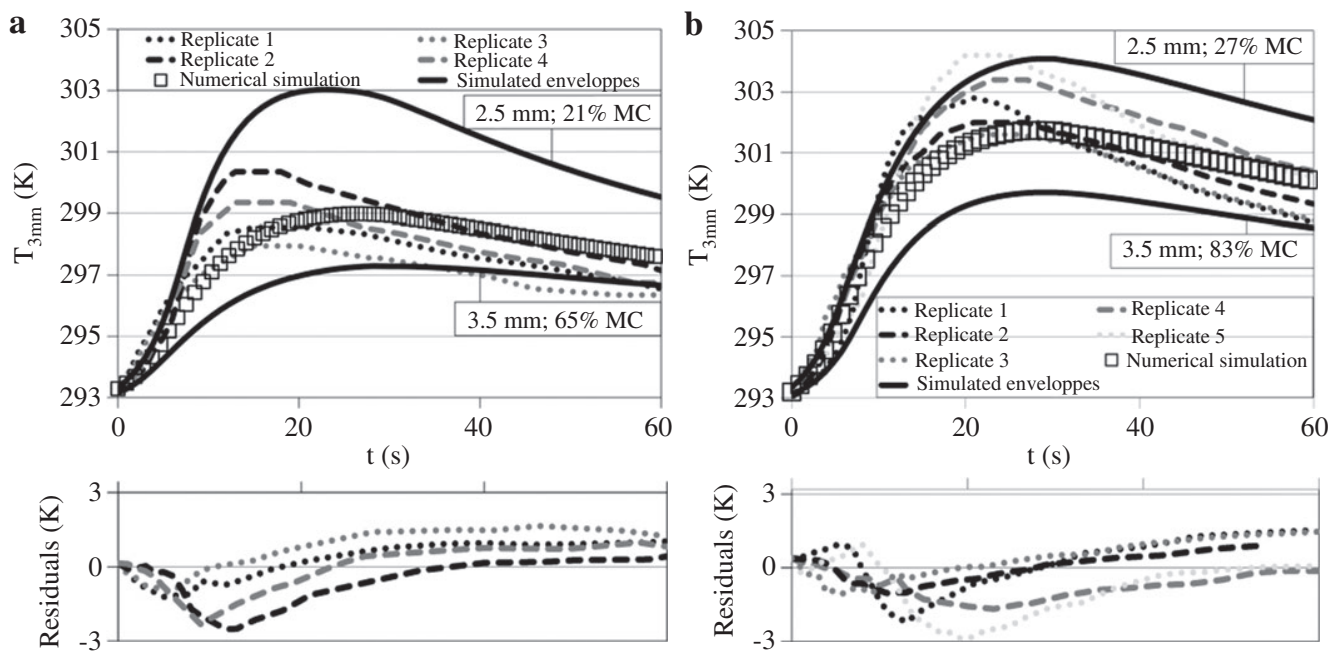

Figure 7 Comparison of experimental results measured at a depth of $3 \mathrm{~mm}$ with numerical simulation curves of temperatures $\mathrm{T}_{3 \mathrm{~mm}}=\mathrm{f}(\mathrm{t})$ and their envelopes $\mathrm{T}_{3 \pm 0.5 \mathrm{~mm}}=\mathrm{f}(\mathrm{t})$ (dotted lines) obtained on different replicates of (a) beech at $43 \pm 22 \% \mathrm{MC}$ and (b) spruce at $55 \pm 28 \% \mathrm{MC}$ (residuals are plotted below each graph).

\section{Conclusion}

By comparing experimental results to those obtained by numerical simulation, the validity of the numerical model developed by Dupleix et al. (2012a) could be confirmed. The approach is based on finite elements to simulate 2D heat transfer within a log and the temporal evolution of temperature on the surface and below the surface. The simplified approach seems to be realistic, and the simple analytical Eqs. (6) and (7) led to acceptable data. The inputs are the thermal and physical properties of green wood and the HFD of the IR source. With the analytical equations provided in this article, it is possible to calculate rapidly (1) the maximum surface temperature reached by a green $\log$ with thermal characteristics, $\lambda$, and $\rho c$, rotating at a peeling speed (s) under an IR heating source (HFD q and width $\mathrm{x}$ ) and (2) the temperature at a certain depth below the surface. The achievable heating rate is insufficient for most of today's industrial peeling speeds. On the contrary, the development of the IR technique should not be stopped because of its assets, such as avoiding the lengthy soaking times and the high investment cost for the soaking basins.

Acknowledgments: This study was partly carried out in Aalto University (Finland), LaBoMaP-Arts et Metiers ParisTech Cluny (France), and I2M (France). The authors are thankful to these institutions for their support and to the RYM-TO Doctoral School for the financial support.

Received June 13, 2013; accepted March 4, 2014; previously published online $x x$

\section{References}

Beck, J.V., St Clair, C.R., Blackwell, B. Inverse Heat Conduction. John Wiley and Sons, Inc., New York, 1985.

Bédard, N., Laganière, B. (2009) Debarking enhancement of frozen logs. Part II: infrared system for heating logs prior to debarking. For. Prod. J. 59:25-30.

Braham-Bouchnak, T., Germain, G., Morel, A., Lebrun, J.L. (2013) The influence of laser assistance on the machinability of the titanium alloy Ti555-3. Int. J. Adv. Manuf. Technol. 68: 2471-2481.
Cserta, E., Hegedüs, G., Németh, R. (2012) Evolution of temperature and moisture profiles of wood exposed to infrared radiation. Bioresources 7:5304-5311.

Coste, N. (2005) Interest of radiant energy for wood peeling and slicing processes. Master's thesis, Arts et Metiers ParisTech.

Dupleix, A., Marchal, R., Bléron, L., Rossi, F., Hughes, M. (2011) On-line heating temperatures of green-wood prior to peeling. Joint International Symposium on Wood Composites and Veneer Processing and Products Proceedings. 
Dupleix, A., Ahmedou, S.A.O., Bléron, L., Rossi, F., Hughes, M. (2012a) Rational production of veneer by IR-heating of green wood during peeling: modeling experiments. Holzforschung 67:53-58.

Dupleix, A., Denaud, L., Bleron, L., Marchal, R., Hughes, M. (2012b) The effect of log heating temperature on the peeling process and veneer quality: beech, birch and spruce case studies. Eur. J. Wood Prod. 71:163-171.

Dupleix, A., De Sousa Meneses, D., Hughes, M., Marchal, R. (2012c) Mid infrared absorption properties of green wood. Wood Sci. Technol. 47:1231-1241.

Dupleix, A., Kusiak, A., Hughes, M., Rossi, F. (2012d) Measuring the thermal properties of green wood by the transient plane source (TPS) technique. Holzforschung 67:437-445.

Grimhall, C.G., Hoel, O. (1983) Method of slicing veneer U.S. Patent No. 4,516,614. Filed June 3, 1983, and issued May 14, 1985.
Marchal, R., Gaudillière, C., Collet, R. (2004) Technical feasibility of an embedded wood heating device on the slicer or the peeling lathe. 1st International Symposium Veneer Processing and Products Proceedings 29-44.

Makoviny, I., Zemiar, J. (2004) Heating of wood surface layers by infrared and microwave radiation. Wood Res. 49:33-40.

Rahman Rashid, R.A., Sun, S., Wang, G., Dargusch, M.S. (2012) The effect of laser power on the machinability of the Ti-6Cr-5Mo$5 \mathrm{~V}-4 \mathrm{Al}$ beta titanium alloy during laser assisted machining. Int. J. Mach. Tool Manuf. 63:41-43.

Suleiman, B.M., Larfeldt, J., Leckner, B., Gustavsson, M. (1999) Thermal conductivity and diffusivity of wood. Wood Sci. Technol. 33:465-473.

Taler, J., Duda, P. Solving Direct and Inverse Heat Conduction Problems. Springer, Berlin, 2006. 